\title{
Operational-Condition-Independent Criteria Dedicated to Monitoring Wind Turbine Generators
}

\author{
Wenxian Yang ${ }^{1}$, Shuangwen Sheng ${ }^{2}$, and Richard Court $^{3}$ \\ ${ }^{1}$ School of Marine Science and Technology, Newcastle University, Newcastle upon Tyne, NE1 7RU, UK \\ wxwyyang@gmail.com \\ ${ }^{2}$ National Renewable Energy Laboratory, Golden, CO, 80401, USA \\ shuangwen.sheng@nrel.gov \\ ${ }^{3}$ National Renewable Energy Center, Blyth, Northumberland, NE24 1LZ, UK \\ richard.court@narec.co.uk
}

\begin{abstract}
Condition monitoring is beneficial to the wind industry for both land-based and offshore plants. However, because of the variations in operational conditions, its potential has not been fully explored. There is a need to develop an operational-condition-independent condition monitoring technique, which has motivated the research presented here. In this paper, three operational-condition-independent criteria are developed. The criteria accomplish the condition monitoring by analyzing the wind turbine electrical signals in the time domain. Therefore, they are simple to calculate and ideal for online use. All proposed criteria were tested through both simulated and practical experiments, showing that these criteria not only provide a solution for detecting both mechanical and electrical faults that occur in wind turbine generators, but that they provide a potential tool for diagnosing generator winding faults.
\end{abstract}

\section{INTRODUCTION}

The wind industry continues to grow worldwide. In particular, offshore wind is attracting increasing interest because of its high and stable wind speed, and lack of significant visual impact and noise issues. Take the offshore wind resource in the United Kingdom (UK) as an example-with 18 sites and a total electric-generating capacity of 1.5 gigawatts $(\mathrm{GW})$, the government launched the first round of offshore wind farm development plans in 2000. To date, 11 Round 1 offshore wind farms are fully operational, with a combined electric-generating capacity of

\footnotetext{
Wenxian Yang et al. This is an open-access article distributed under the terms of the Creative Commons Attribution 3.0 United States License, which permits unrestricted use, distribution, and reproduction in any medium, provided the original author and source are credited.
}

876 megawatts (MW). The 90-MW Teesside wind farm has been recently consented. Following Round 1, the government launched a plan for a second round of larger sites in 2003. In Round 2, 16 sites were awarded, totaling a combined capacity of up to $7.2 \mathrm{GW}$. Today, two Round 2 offshore wind farms (Gunfleet Sands II $64 \mathrm{MW}$ and Thanet $300 \mathrm{MW}$ ) are fully operational, five are under construction, three were consented, and the other six are in planning. Subsequently, the UK offshore wind Round 3 scheme was announced in 2008, offering nine development zones and a total electric-generating capacity of $32 \mathrm{GW}$ - equaling onefourth of the UK's electricity needs. From these data, it can be inferred that large megawatt-scaled wind turbines are being increasingly deployed offshore. Moreover, the locations where the wind farms are deployed tend to increase in size and distance from shore. Hence, wind turbine operators are very concerned about the reliability and availability issues of these offshore giants. The early experience of UK Round 1 offshore wind farms (Feng, Tavner, and Long, 2010) shows that although these farms achieve satisfactory capacity factors (about 29.5\%), their annual average availability is only $80.2 \%$. This is fairly low in comparison to the average availability of UK land-based wind farms (97\%).

Apparently, the low availability has become a barrier to reducing the cost of energy from offshore wind. For example, the Barrow site, a standard UK Round 1 offshore wind farm, includes:

- A rated power of $90 \mathrm{MW}$

- An annual average capacity factor of $29.5 \%$

- A tariff rate of $\$ 117$ (USD) per megawatt-hour (MWh).

The annual revenue of this wind farm can be estimated by $90 \mathrm{MW} \times 365$ days/year $\times 24$ hours/day $\times 29.5 \% \times$ 
$117 \mathrm{USD} / \mathrm{MWh} \approx 27.2$ million USD. Then it can be readily supposed that this wind farm will yield $\$ 272,000$ USD more annual revenue if its production can be improved by $1 \%$. For the future 32-GW UK Round 3 offshore wind development scheme, a $1 \%$ improvement in production could yield more than 9.7 billion USD per year. Undoubtedly, this is a significant economic profit to operators. In practice, there are many methods that can be used to improve wind turbine availability. Specifically, condition monitoring $(\mathrm{CM})$ has been proven as one of the most efficient methods (Yang, Tavner, Crabtree, Feng, and Qiu, 2012; McMillan and Ault, 2007). The additional value of a proper wind turbine condition-monitoring system (CMS) is observable from detecting the incipient faults occurring in wind turbines and their subassemblies, protecting the defective parts from second-damage, and preventing fatal, catastrophic wind turbine accidents. The additional value can also be justified by the following actual wind turbine operation and maintenance (O\&M) data. In the commercial market today, the component replacement costs for a 5-MW turbine include the following (McMillan \& Ault, 2007; BVG Associates, 2011):

- For a rotor: 1.9-2.3 million USD

- For a blade: 391-547 thousand USD

- For a blade bearing: 62.5-78.2 thousand USD

- For a gearbox: 628 thousand USD

- For a generator: 314 thousand USD

- For electronic modules: 16 thousand USD.

By contrast, the current average market price of a CMS is only around $\$ 16,000$ USD per unit. As a result, it may be worthwhile to equip offshore wind turbines with a CMS to ensure the turbine's anticipated availability and economic return.

However, wind practice shows that the wind turbine CMSs that are currently available in the market have not been as successful as expected at improving wind turbine availability. The reasons are complicated (Yang, Tavner, Crabtree, Feng, and Qiu, 2012), but one of the major reasons is that the available CMSs are using the generalpurpose $\mathrm{CM}$ techniques, which are unable to provide reliable CM results for wind turbines. Because wind turbines operate at variable rotational speeds and are constantly subjected to varying loads, these influences and the effects of potential faults are combined in wind turbine CM signals, which makes it difficult to interpret the signals and reduces the reliability of the CM results. Although there have been some recent efforts in this respect (Yang, Court, Tavner, and Crabtree, 2011; Yang, Tavner, Crabtree, and Wilkinson, 2010), frequent false alarms generated by the wind turbine CMS still overwhelm the operators and make them hesitant to use CMS extensively on their machines. Therefore, it is necessary to remove the negative influences of varying loads and rotational speeds on wind turbine CM results in order to use CMS to improve wind turbine availability. Two straightforward approaches can serve as a solution: 1) introduce operational-condition decoupling procedures into the current wind turbine $\mathrm{CM}$ techniques, or 2) develop new operational-condition-independent wind turbine CM techniques. Considering the complexities and difficulties in realizing the first approach, this paper demonstrates the second approach for simplicity. Thereby, the work presented in the paper will focus on monitoring wind turbine induction generators under continuously varying operational conditions.

\section{OPERATIONAL-CONDITION-INDEPENDENT CONDITION MONITORING CRITERIA}

To achieve a reliable CM technique that is dedicated for wind turbine induction generators that experience constantly varying operational conditions, the following criteria were researched.

\subsection{Criterion $\delta$}

For a wind turbine induction generator, neither varying load nor potential faults are able to influence the primary frequency of its stator current signal. But the sub- or higherorder of fault-related harmonics will distort the time waveform of the stator current signal and thus disturb its zero-crossing behavior; whereas, the zero-crossing behavior of stator current signal is less dependent on load because varying load mainly affects the amplitude of the signal. With this knowledge, the first $\mathrm{CM}$ criterion, $\delta$, was developed to describe the fault effect on the zero-crossing behavior of the stator current signal (see Figure 1). The figure shows the relative phase angles of the generator stator current signal with respect to the corresponding voltage signal in various scenarios. $I_{l}$ represents the line current signal measured at phase 1 of generator stator, $V_{I}$ represents the corresponding phase voltage signal, and $\Delta t$ represents the leading/lagging time of $I_{l}$, with respect to $V_{l}$.

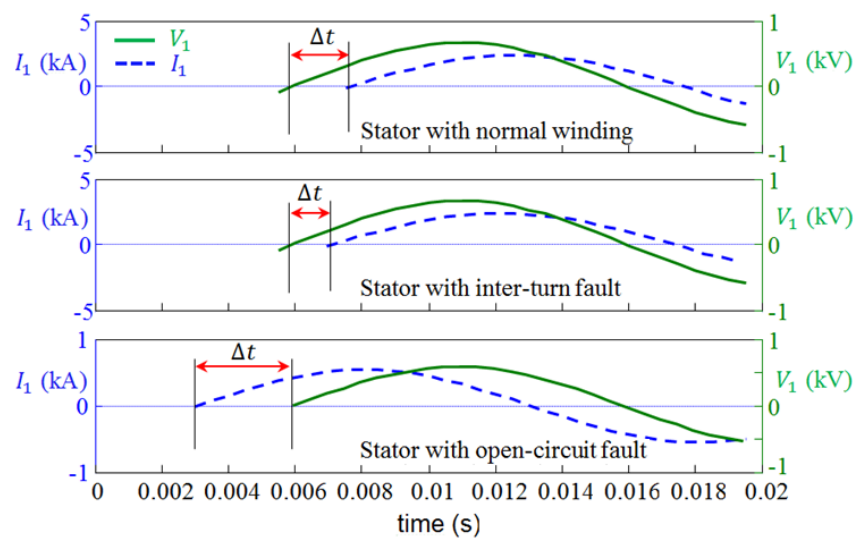

Figure 1. Zero-crossing behavior of the stator current signal in different scenarios

As Figure 1 shows, the potential generator winding faults will either increase or decrease the value of $\Delta t$, thus 
disturbing the zero-crossing behavior of its stator current signal. So potentially, $\Delta t$ can be an indicator of the health of a wind turbine induction generator. However, $\Delta t$ is not accurate enough to be a $\mathrm{CM}$ criterion. It only reflects the shift of the current signal and it does not exactly show how much the phase shift is with respect to the corresponding voltage signal. In other words, the same value of $\Delta t$ might indicate a different level of phase shift of the current signal when the grid frequency is different (either 50 hertz [Hz] or $60 \mathrm{~Hz}$, depending on the areas). Therefore, an improvement of $\Delta t$ occurs by normalizing $\Delta t$ using the frequency of mains electricity. Hence, a new $\mathrm{CM}$ criterion, $\delta$, is designed as:

$$
\delta=\frac{\Delta t}{T} \times 360^{\circ}
$$

where

$$
T=\frac{1}{f_{\text {grid }}}
$$

$f_{\text {grid }}$ refers to the frequency of mains electricity.

From a physics point of view, $\delta$ is less dependent on the external load applied to the generator because it is only related to the impedance status and the magnetizing behavior of the generator. However, the potential faults occurring in an induction generator will disturb its circuit impedance or ability to magnetize. In other words:

- Either an inter-turn or open-circuit winding fault occurring in the generator rotor or stator will change the impedance of the generator circuit, thus leading to the change of criterion $\delta$

- The generator mechanical faults, usually related to rotor shaft, bearings, and air-gap eccentricity, will alter the rotor-to-stator air gap statically or dynamically. Then, the modified air gap will result in the change of the magnetizing current of the generator. Correspondingly, criterion $\delta$ will change.

Therefore, criterion $\delta$ should be able to send an alert of both electrical and mechanical faults occurring in the generator. However, it should be noted that double-fed induction generators (DFIG) have the capability to correct power factor on the grid and therefore the value of $\delta$, particularly when the grid has a large inductive load. This would more or less affect the capability of the proposed method in detecting incipient faults occurring in the generators. So further research could be needed to improve the efficiency of the proposed technique in DFIG cases.

\subsection{Criterion $r$}

As mentioned above, both varying load and generator abnormalities will influence the power (and power quality) output from a wind turbine induction generator. The difference is that varying load can alter the power but not the physical performance of the generator; however, the generator abnormalities can alter both. For example, a generator winding fault can change the circuit impedance of an induction generator, whereas an external load cannot. So the circuit impedance of an induction generator is loadindependent. But it can be a challenge to accurately measure generator circuit impedance online. In addition, there is a lack of control over uncertainties related to slip rings or carbon brushes. The metering accuracy and sensitivity of the data acquisition instruments are also concerns. In response to these issues, an alternative criterion, $r$, was developed for the purpose of indicating the status of the circuit impedance of an induction generator. It is based on a statistical calculation of the generator stator line current and the corresponding voltage signals. The criterion $r(t)$, expressed in terms of line current $I_{l}(t)$ and the corresponding phase voltage $V_{l}(t)$, can be written as:

$$
r(t)=\sqrt{\frac{\sum_{\delta t=-\tau / 2}^{\tau / 2}\left[V_{1}(t+\delta t)\right]^{2}}{\sum_{\delta t=-\tau / 2}^{\tau / 2}\left[I_{1}(t+\delta t)\right]^{2}}}
$$

where a sliding window with the width of $\tau$ is used in the calculation. Subscript ' 1 ' indicates the phase 1 of the generator stator. The criterion can also be assessed by using the electrical signals measured from phase 2 or phase 3 of the generator stator.

Inter-turn or open-circuit faults that occur in the winding of the generator rotor or stator will change the circuit impedance of the generator. Therefore, researchers believe that this change should be observable from criterion $r$. The generator shaft and bearing-related faults will statically or dynamically alter the rotor-to-stator eccentricity, which will affect the magnetizing current of the generator. As a result, criterion $r$ will change as well.

In principle, criterion $r$ is load-independent and valid for detecting both electrical and mechanical faults that occur in wind turbine induction generators.

\subsection{Criterion $e$}

Park's vector (Cardoso \& Saraiva, 1993) successfully describes the three-phase phenomenon in a two-dimensional coordinate system that allows the pattern-based CM of three-phase induction motors (Nejjari \& Benbouzid, 2000). This technique can be applied to the CM of three-phase induction generators. The current Park's vector components $\left(i_{d}, i_{q}\right)$ can be calculated by:

$$
\left\{\begin{array}{l}
i_{d}=\sqrt{\frac{2}{3}} I_{1}-\frac{1}{\sqrt{6}} I_{2}-\frac{1}{\sqrt{6}} I_{3} \\
i_{q}=\frac{1}{\sqrt{2}} I_{2}-\frac{1}{\sqrt{2}} I_{3}
\end{array}\right.
$$


where $I_{1}, I_{2}$, and $I_{3}$ represent the line currents measured from the stator of a three-phase generator/motor.

When the health condition of the generator is without any defect, $\left(i_{d}, i_{q}\right)$ is characterized by a circle pattern that is centered at the origin of the coordinate system. The size of the circle is related to the power generated by the generator. For example, the larger the power, the bigger the circle. Apparently, the pattern depicted by $\left(i_{d}, i_{q}\right)$ is loaddependent. So if $i_{d}$ and $i_{q}$ are applied directly to CM application (as done by Nejjari and Benbouzid, 2000), it is hard to get a creditable $\mathrm{CM}$ result under a varying loading condition. To help alleviate this issue, a further improvement is provided below.

Because the external load will change the values of $I_{1}, I_{2}$, and $I_{3}$, it will affect the values of $i_{d}$ and $i_{q}$ and the size of the pattern depicted by $\left(i_{d}, i_{q}\right)$. However, external load is unable to change the eccentricity and roughness of the pattern curve, which are only dependent on the balance status of the generator load (i.e., the balance of three phases) and the harmonics (either sub- or higher order) that are induced by the faults. Therefore, the pattern eccentricity and the roughness of its curve are load-independent and have the potential to be used for generator CM. To provide a comprehensive description of the pattern eccentricity and curve roughness, a new CM criterion, $e$, is developed:

$$
e(t)=\frac{R_{\max }(t)-R_{\min }(t)}{\bar{R}(t)} \times 100 \%
$$

where

$$
\begin{gathered}
\bar{R}(t)=\frac{1}{T} \int_{t-T / 2}^{t+T / 2} R(\tau) d \tau \\
R(\tau)=\left|i_{d}(\tau)+j \times i_{q}(\tau)\right| \\
R_{\text {max }}(t)=\max (R(\tau)), \tau \in[t-T / 2, t+T / 2] \\
R_{\text {min }}(t)=\min (R(\tau)), \tau \in[t-T / 2, t+T / 2]
\end{gathered}
$$

$T$ stands for the frequency period of grid.

\section{FAUlt Simulations}

To verify the CM criteria, both inter-turn and open-circuit faults are simulated on the rotor and stator windings of an induction generator by using Simulink. The winding fault simulation model is shown in Figure 2, and the parameters of the generator being simulated are listed in Table 1 . In the experiment, the winding faults are simulated by introducing electrical asymmetry into the generator rotor and stator circuit, and the CM signals (i.e., line currents, phase voltages, and total power) are measured from the stator of the generator.

In Figure 2, $L$ refers to the inductance and $R_{1}$ refers to the resistance of the transmission line. $R_{2}=1 \mathrm{e} 3 \Omega$ represents the phase resistance to the ground. In the model, resistances $R_{3}$ and $R_{4}$ are specially designed to introduce electrical asymmetries into the stator and rotor of the generator. The initial values are $R_{3}=1.16 \mathrm{e}-3 \Omega$ and $R_{4}=3.92 \mathrm{e}-2 \Omega$ in the absence of electrical asymmetry.

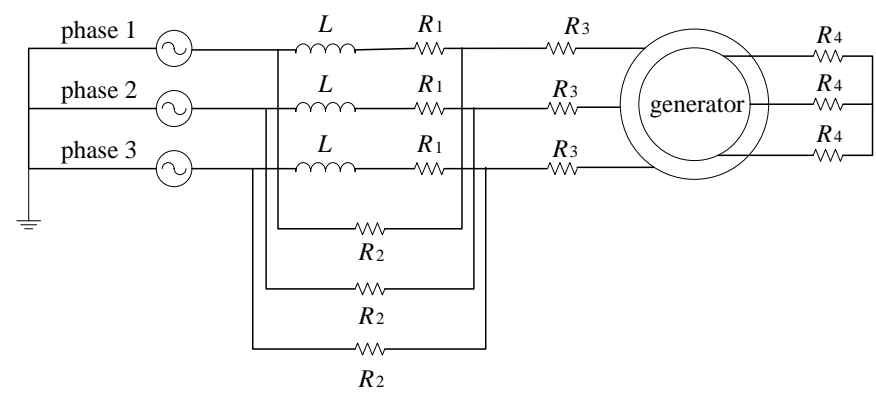

Figure 2. Model for simulating generator winding faults

\begin{tabular}{|l|l|l|l|}
\hline Parameter & Value & Parameter & Value \\
\hline Rated power, $S_{b}$ & $2 \mathrm{MW}$ & $\begin{array}{l}\text { Rotor leakage } \\
\text { inductance, } L_{r}^{*}\end{array}$ & $1.493 \mathrm{e}-1$ p.u. \\
\hline $\begin{array}{l}\text { Line-line } \\
\text { voltage, } V_{n}\end{array}$ & 690 volts $(\mathrm{V})$ & $\begin{array}{l}\text { Magnetizing } \\
\text { inductance, } L_{m}^{*}\end{array}$ & 3.9527 p.u. \\
\hline $\begin{array}{l}\text { Rated frequency, } \\
f_{b}\end{array}$ & $50 \mathrm{~Hz}$ & $\begin{array}{l}\text { Winding } \\
\text { connection } \\
\text { (stator/rotor) }\end{array}$ & $\mathrm{Y}-\mathrm{Y}$ \\
\hline $\begin{array}{l}\text { Stator resistance, } \\
R_{S}^{*}\end{array}$ & $4.88 \mathrm{e}-3$ p.u. & $\begin{array}{l}\text { Turns ratio } \\
\left(N_{s} / N_{r}\right)\end{array}$ & 0.45 \\
\hline $\begin{array}{l}\text { Stator leakage } \\
\text { inductance, } L_{s}^{*}\end{array}$ & $1.386 \mathrm{e}-1$ p.u. & Inertia & $32 \mathrm{Kg} \cdot \mathrm{m}^{2}$ \\
\hline $\begin{array}{l}\text { Rotor resistance, } \\
R_{r}^{*}\end{array}$ & $5.49 \mathrm{e}-3$ p.u. & Friction & $\begin{array}{l}2.985 \mathrm{e}-4 \\
\mathrm{~N} \cdot \mathrm{m} \cdot \mathrm{s}\end{array}$ \\
\hline
\end{tabular}

Table 1. The parameters used for simulating an induction generator (Xiang, Ran, Tavner, and Yang, 2006).

Based on the parameters listed in Table 1, the transmission line impedance can be estimated as:

$$
R_{1}+j L=0.01 Z_{s b}+j \times 0.1 L_{s b}
$$

where

$$
\begin{gathered}
Z_{s b}=\frac{V_{s b}}{I_{s b}} \\
V_{s b}=\sqrt{\frac{2}{3}} V_{n} \\
I_{s b}=\sqrt{\frac{2}{3} \times \frac{S_{b}}{V_{n}}} \\
L_{s b}=\frac{Z_{s b}}{2 \pi f_{b}}
\end{gathered}
$$


By submitting (11)-(14) into (10), obtain $R_{1}=2.3805 \mathrm{e}-3 \Omega$ and $L=7.6 \mathrm{e}-5 \mathrm{H}$.

\subsection{Winding Faults in Rotor}

The inter-turn and open-circuit faults are simulated first in the generator rotor by setting the resistance in the second phase to $\mathrm{R}_{4}=3.92 \mathrm{e}-3 \Omega$ and $\mathrm{R}_{4}=3.92 \mathrm{e}-1 \Omega$. The resulting electrical signals and the corresponding $\mathrm{CM}$ results are shown in Figure 3.

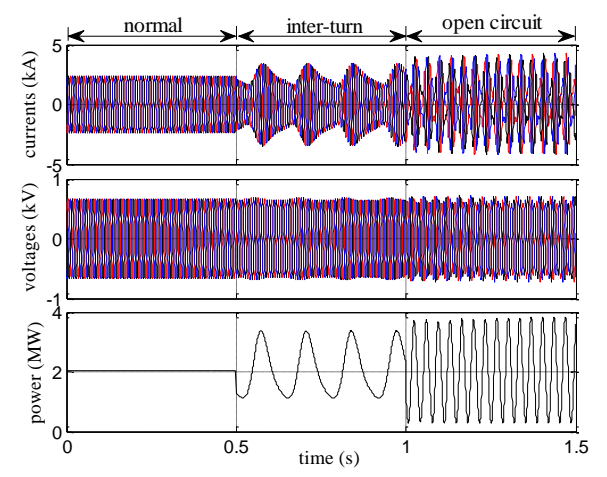

(a) Electrical signals

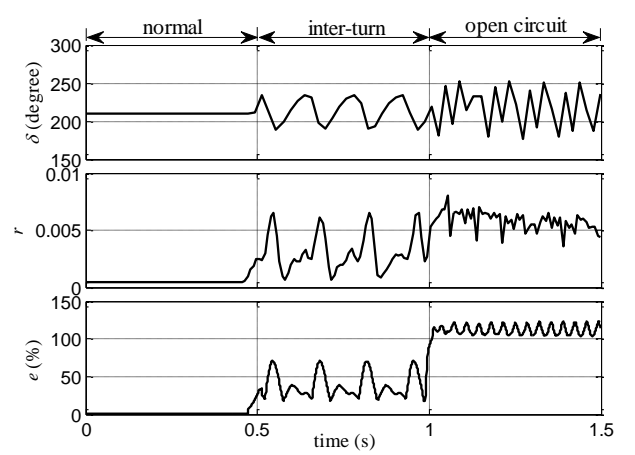

(b) CM results

Figure 3. Simulation and CM of generator rotor winding faults

Figure 3(a) shows that both the inter-turn and open-circuit faults that occur in the rotor significantly distort the timewaveforms of stator current signals, but have less of an effect on the time-waveforms of stator voltage signals. This is because the generator voltage is mainly dominated by the grid's voltage, whereas the generator stator current is a different matter. The generator stator current is not only dependent on the generator's external load and operational condition, but on its actual health status. Researchers also noticed that the total power signal appears in direct current (DC) form when the generator is healthy and without any winding defect and appears in alternating current (AC) form time-waveforms in the presence of either inter-turn or opencircuit winding faults. In addition, researchers found that the power signals that were collected in two fault scenarios show distinctly different pattern features. For example, the power fluctuates slowly along time in the presence of an inter-turn fault, but fluctuates quickly in the presence of an open-circuit fault. Similar phenomena can also be observed from the time-waveforms of the current signals. The two types of rotor winding faults have different characteristic frequencies in generator electrical signals. This could be important information, not only to the generator's CM but also to its fault diagnosis.

Figure 3(b) shows that all three proposed CM criteria are aware of the presence of both types of rotor winding faults, although the faults display different variation characteristics in different scenarios. The CM results shown in Figure $3 \mathrm{~b}$ prove that the winding faults that occur in the generator rotor will:

- Disturb the zero-crossing behaviour of generator stator current signal (characterized by criterion $\delta$ )

- Change the circuit impedance of the generator (characterized by criterion $r$ )

- Cause load imbalance to the generator (characterized by criterion $e$ ).

\subsection{Winding Faults in Stator}

The inter-turn and open-circuit faults are simulated in the stator of the generator by setting the resistance in its second phase to $R 3=1.16 \mathrm{e}-4 \Omega$ and $\mathrm{R} 3=1.16 \mathrm{e}-2 \Omega$. The electrical signals and corresponding calculation results of $\mathrm{CM}$ criteria are shown in Figure 4.

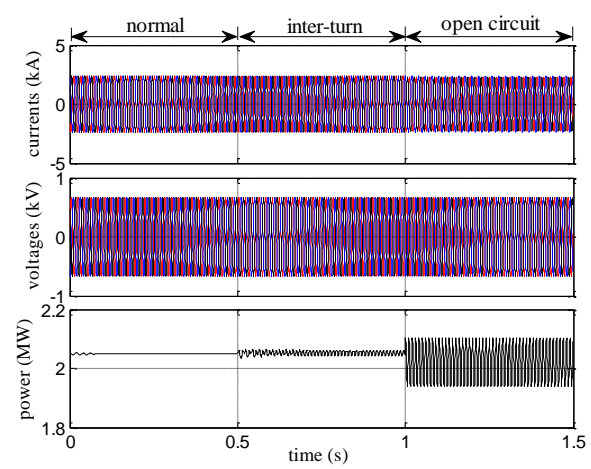

(a) Electrical signals

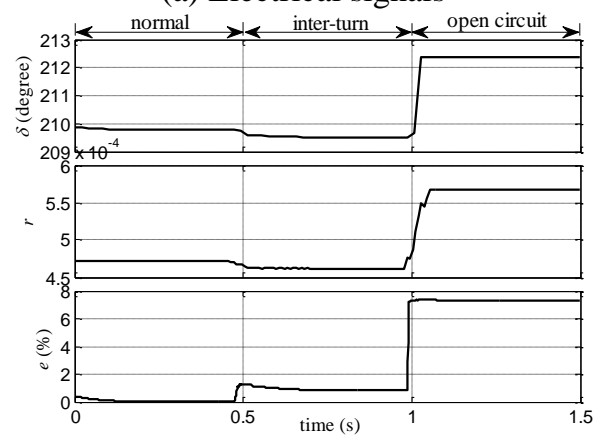

(b) $\mathrm{CM}$ results

Figure 4. Simulation and CM of generator stator winding faults 
Figure 4(a) shows that, compared to the winding faults that occur in the generator rotor, both inter-turn and open-circuit faults that occur in the generator stator do not have a significant effect on the time-waveforms of stator current and voltage signals. However, like a generator rotor winding fault, they create a load imbalance in the generator, which is characterized by the $\mathrm{AC}$ form of power signal.

Figure 4(b) shows that all three proposed CM criteria are equally sensitive to both types of stator winding faults. For example:

- An inter-turn circuit fault decreases the value of criterion $\delta$ while an open-circuit fault increases it. This finding further supports the phase shift phenomena of the current signal shown in Figure 1.

- An inter-turn circuit fault decreases the circuit impedance of the generator whereas an opencircuit fault increases it.

- Both inter-turn and open-circuit faults change the pattern depicted by Park's vector $\left(i_{d}, i_{q}\right)$, thus changing criterion $e$.

\section{VERIFICATION EXPERIMENTS}

The verification experiments were conducted on a 30kilowatt $(\mathrm{kW})$, three-phase, four-pole induction generator, which was driven by a 54-kW, DC-variable speed motor through a two-stage gearbox with a gear ratio of 1:5. To emulate faults, the rotor circuit of the generator was coupled to an externally connected, three-phase resistive load bank (see Figure 5). As a result, electrical asymmetry could be readily applied to the generator rotor by adjusting the phase resistances of the load bank. The test rig was instrumented and controlled using LabVIEW, allowing researchers to apply a variety of wind speed inputs to the test rig via the DC motor. The rotational speed of the DC motor was controlled by a mathematical model that incorporates the properties of natural wind at different wind speeds and the mechanical behavior of a 2-MW wind turbine operating under closed-loop control conditions. More details about this test rig are provided in Yang, Tavner \& Court (2013). In the experiment, both fixed and variable rotational speeds were applied to the DC motor and generator to verify the capabilities of the three proposed CM criteria under various loading conditions.

Researchers verified and applied the CM criteria when monitoring the generator at a fixed rotational speed of 1,750 revolutions per minute (rpm). In addition, researchers periodically applied a winding fault to the generator's rotor by repeatedly adjusting the phase resistances of the load bank. The electrical signals were collected from the generator terminals by using a sampling frequency of 5 kilohertz $(\mathrm{kHz})$. The time-waveforms of the electrical signals and the corresponding CM results are shown in
Figure 6. In the figure, normal represents electrical symmetry and abnormal represents electrical asymmetry.

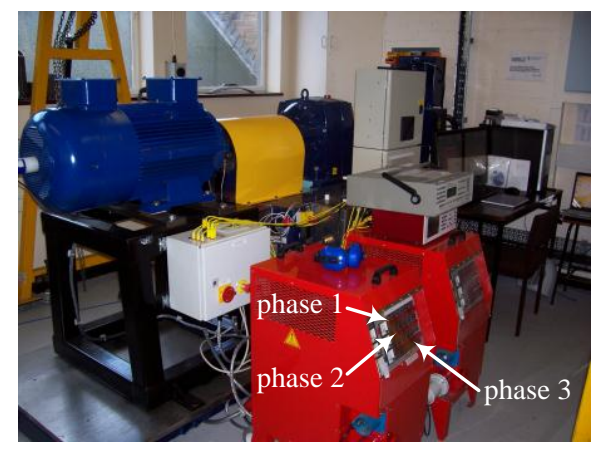

Figure 5. Test rig for conducting verification experiments

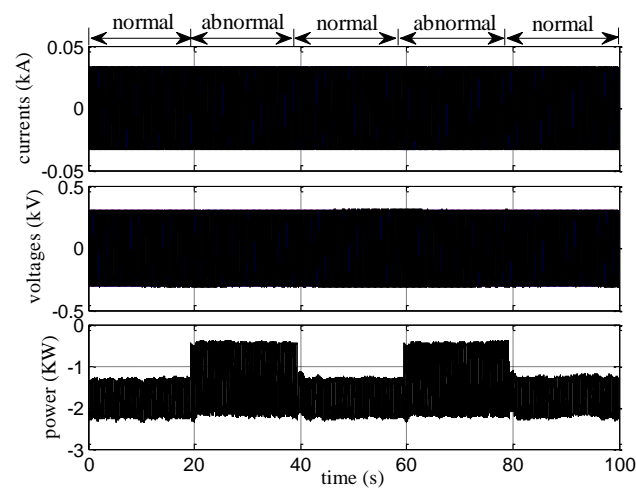

(a) Electrical signals

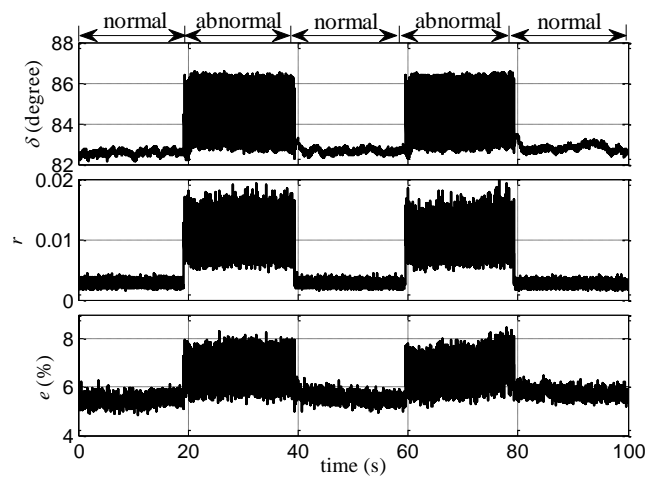

(b) CM results

Figure 6. CM when generator rotates at constant rotational speed

Compared to Figure 3(a), the emulated rotor winding fault shown in Figure 6(a) does not disturb the time-waveform of the stator current signal as anticipated. This is because the asymmetry that is introduced by the load bank is too small to be observable from the measured current signal. To confirm this, the current signal shown in Figure 6(a) was amplified 40 times. The amplified time-waveform of the current signal is shown in Figure 7, from which the waveform distortion that was caused by the asymmetry has already been clearly visible. So it is demonstrated, once 
again, that the winding fault that occurs in the induction generator's rotor distorts the time-waveform of its stator current signal. Compared to the effect of the winding fault on generator stator current signal, the effect of the distortion on generator total power is much more significant. In Figure 6(a), a big distortion of generator power signal happens as soon as the fault occurs, and the power returns back to its normal waveform immediately when the fault goes away. This suggests that, in comparison to the stator current signal, the generator total power signal is more sensitive to the fault. This is why the generator power signal, rather than the stator current signal, was adopted in Yang, Tavner, Crabtree, and Wilkinson (2010) for wind turbine condition monitoring even though the majority of existing motor/generator CM techniques are based on the analysis of stator current signals (Tavner, 2008).

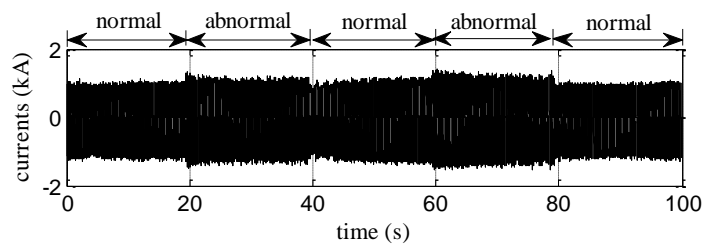

Figure 7. Amplified time-waveform of the stator current signal

In Figure 6(b), the winding fault has been successfully detected by all three proposed CM criteria, although these criteria are developed based on the analysis of the stator current and voltage signals.

To further verify the CM capability of the proposed criteria under varying loading conditions, as observed from real wind turbines, researchers repeated the experiment when the DC motor was controlled to operate at constantly varying speeds. As part of this process, the electrical signals (i.e., stator current, voltage, and total power) were collected from the generator terminals by using the same sampling frequency of $5 \mathrm{kHz}$. The time-waveforms of these $\mathrm{CM}$ signals and the corresponding results are shown in Figure 8.

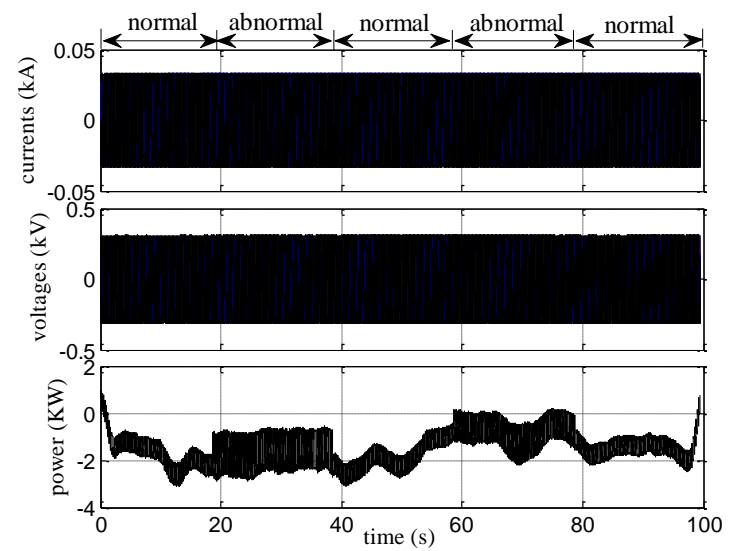

(a) Electrical signals

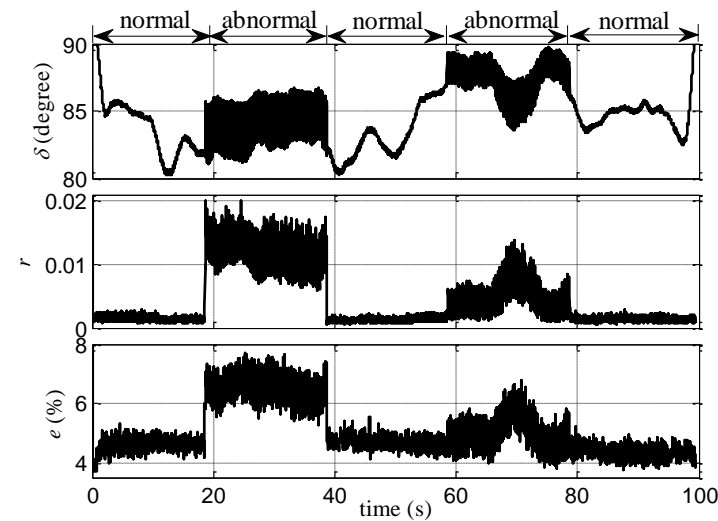

(b) CM results

Figure 8. CM when the generator rotates at a varying rotational speed

Figure 8(a) shows that, not only is the winding fault undetected by the time-waveforms of the stator current and voltage signals, but it is undetected by the generator power signal because of the negative influence of varying loads. Nonetheless, the fault is detected successfully by using the three proposed CM criteria (see Figure 8(b)). Still, the result of criterion $\delta$ is not completely load-independent, and therefore a de-trending process is necessary.

\section{Conclusions}

In this paper, researchers first discussed the influences of various types of winding faults on an induction generator. Three operational-condition-independent CM criteria were researched to achieve a reliable $\mathrm{CM}$ of a wind turbine generator that is usually subjected to constantly varying loads. Based on this work, researchers came to the following conclusions:

- Winding faults that occur in a generator rotor will distort the time-waveform of the generator stator current signal, but the faults have less influence on the stator voltage signal.

- Compared to the stator current and voltage signals, the generator total power signal is more alert to the presence of generator faults.

- $\quad$ All three proposed CM criteria are able to successfully detect the generator winding faults despite the loading conditions. However, experimental results indicate that criterion $\delta$ is not completely load-independent. Under varying loading conditions, an additional de-trending of the criterion could be necessary to further improve its fault detection capability.

- Experimental results suggest that different types of rotor winding faults show different characteristics in the stator current signal. This is potentially important information to both $\mathrm{CM}$ and fault diagnosis of the induction generator. 
Following this work, the future effort will continue to validate the proposed techniques in the cases where (1) a DFIG is connected to the grid with large inductive load; (2) various types of generator faults happen simultaneously; and (3) the generator faults deteriorate with time.

\section{ACKNOWLEDGEMENT}

The work presented in this paper was funded by the European FP7 project OPTIMUS 322430 and the China Natural Science Foundation, with the project reference number of 51075331.

\section{REFERENCES}

BVG Associates (2011). A guide to an offshore wind farm.

Cardoso, A.J.M., \& Saraiva, E.S. (1993). Computer-aided detection of airgap eccentricity in operating three-phase induction motors by Park's vector approach. IEEE Transactions on Industry Applications, vol.29, no.5, pp.897-901.

Feng, Y., Tavner, P., \& Long, H. (2010). Early experiences with UK Round 1 offshore wind farms. Proceedings of the Institution of Civil Engineers: Energy, vol.163, no.4, pp.167-181.

McMillan, D., \& Ault, G.W. (2007). Quantification of condition monitoring benefit for offshore wind turbines. Wind Engineering, vol.31, no.4, pp.267-285.

Nejjari, H., \& Benbouzid, M.E.H. (2000). Monitoring and diagnosis of induction motors electrical faults using a current Park's vector pattern learning approach. IEEE Transactions on Industry Applications, vol.36, no.3, pp.730-735.

Tavner, P. (2008). Review of condition monitoring of rotating electrical machines. IET Electric Power Applications, vol.2, no.4, pp.215-247.

Xiang, D., Ran, L., Tavner, P., \& Yang, S. (2006). Control of doubly fed induction generator in a wind turbine during grid fault ride-through. IEEE Transactions on Energy Conversion, vol.21, no.3, pp.652-662.

Yang, Wenxian, Tavner, P., Crabtree, C., \& Wilkinson, M.R. (2010). Cost-effective condition monitoring for wind turbines. IEEE Transactions on Industrial Electronics, vol.57, no.1, pp.263-271.

Yang, Wenxian, Court, R., Tavner, P., \& Crabtree, C. (2011). Bivariate empirical mode decomposition and its contribution to wind turbine condition monitoring. Journal of Sound and Vibration, vol.330, no.15, pp.3766-3782.
Yang, Wenxian, Tavner, P., Crabtree, C., Feng, Y., \& Qiu, Y. (2012). Wind turbine condition monitoring: Technical and commercial challenges. Wind Energy, In Press.

Yang, Wenxian, Tavner, P., \& Court, R. (2013). An online technique for condition monitoring the induction generators used in wind and marine turbines. Mechanical Systems and Signal Processing, vol.38, no.1, pp.103-112.

\section{BIOGRAPHIES}

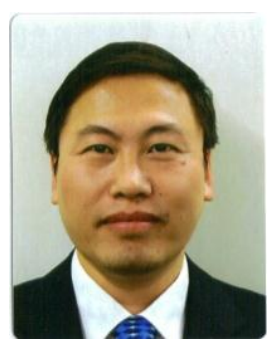

Dr. Wenxian Yang received a Ph.D. in mechanical engineering from Xi'an Jiaotong University, Xi'an, China, in 1999. He is currently a lecturer in offshore renewable energy at Newcastle University. Before lecturing, he worked for the UK National Renewable Energy Centre (NAREC) as a technical specialist, specifically in the areas of new and renewable energy, marine hydrodynamics, offshore structures and installation, signal processing, machine condition monitoring and fault diagnosis, nondestructive testing and evaluation, and artificial intelligence in both industry and academia.

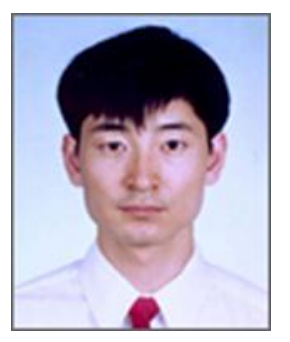

Dr. Shuangwen (Shawn) Sheng is a senior engineer at National Renewable Energy Laboratory (NREL). He has a B.S. and M.S. in electrical engineering and a Ph.D. in mechanical engineering. Shawn is currently leading wind turbine condition monitoring, failure database and wind plant $O \& M$ research at NREL. He also has experience in mechanical and electrical system modeling and analysis, soft computing techniques, and automatic control. He has published his work in various journals, conference proceedings, and book chapters.

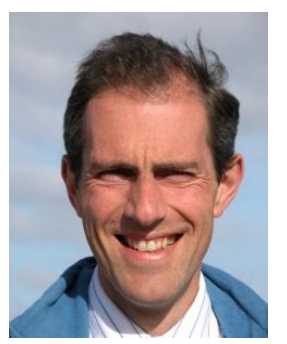

Dr. Richard Court received a Ph.D. in material engineering from Cambridge University in 2001. He is currently the principal wind specialist at NAREC. Dr Court's main expertise is on testing of wind turbine blades with secondary experience of other technologies within the wind sector. 